\title{
Slavernijgeschiedenis zonder polderen: observaties over een debat vol contrasten
}

\author{
Pepijn Brandon ${ }^{*}$
}

In 2012 ontleedde VU-onderzoeker Guno Jones in BMGN/LCHR, het huisblad van Nederlandse vakhistorici, de felle discussie die was uitgebroken naar aanleiding van de NTR-documentairereeks De Slavernij. Hij beschreef het publieke debat dat op de serie volgde als:

'een moment waarop de meer invloedrijke, machtige perspectieven op de geschiedschrijving en representatie van de slavernij werden uitgedaagd door een minder gangbaar postkoloniaal vertoog, dat gedragen werd door een herinneringsgemeenschap en kritische onderzoekers en wetenschappers. Dit postkoloniale vertoog stond op gespannen voet met de makers van de serie en met die historici die een meer geaccepteerd perspectief op het slavernijverleden verwoorden.' (Jones, 2012, 79-80)

Sinds 2012 is er veel verschoven in de slavernijdiscussie. Voor een belangrijk deel is dat het gevolg van de grote maatschappelijke roep om meer - en minder eenzijdig vanuit een 'Nederlands' perspectief beschreven - kennis over het slavernijverleden. Tegelijk is er ook binnen de academische geschiedschrijving sprake van verschuivende inzichten en interesses, die natuurlijk niet los staan van wat er in de samenleving als geheel speelt. Toch is een aantal van de processen die Jones beschreef daarmee niet zomaar verdwenen. Dat heeft er onder andere mee te maken dat het fundamentele karakter van de interpretatieverschillen rond het thema slavernij slecht passen bij de bestaande cultuur van wetenschappelijk debat onder Nederlandse historici. In een recent interview beschrijft hoogleraar Susan Legêne, een specialist op het gebied van de Nederlandse kijk op kolonialisme in Indonesië, dat de reflex van meer gevestigde historici op kritiek doorgaans is om zo snel mogelijk hun eigen gelijk te herbevestigen en zo de discussie te smoren (Mathijssen, 2018). Dit sluit aan op Jones' observatie dat in de positivistisch ingestelde Nederlandse geschiedschrijving het bestaan van grote interpretatieverschillen botst met het idee dat het de taak van de wetenschap is om consensus te produceren over 'de juiste feiten', waarbij in werkelijkheid noch de gepresen-

* Pepijn Brandon is universitair docent sociale en economische geschiedenis aan de VU en senior onderzoeker aan het Internationaal Instituut voor Sociale Geschiedenis (IISG). Hij promoveerde in 2013 op een studie naar de invloed van oorlog op de Nederlandse economie en Staat in de zeventiende en achttiende eeuw. Sindsdien werkte hij in verschillende onderzoeksprojecten over de Atlantische slavernij, onder andere als onderzoeker aan de University of Pittsburgh en als Visiting Fellow aan Harvard. Zijn belangstelling gaat daarbij in het bijzonder uit naar de langetermijngevolgen van slavernij voor arbeidsverhoudingen, (geracialiseerde) sociale controle en kapitalistische ontwikkeling. 
teerde feiten, noch de consensus daarover ooit compleet los kunnen staan van heersende meningen en machtsrelaties (Jones, 2012, 81).

De wijze waarop door Nederlandse beroepshistorici wordt gediscussieerd over het slavernijverleden lijkt daarmee weinig op die in de Verenigde Staten. Veel duidelijker is er daar sprake van niet één of twee, maar een groot aantal botsende scholen in de interpretatie van de slavernij. Zwarte wetenschappers zijn nadrukkelijk aanwezig in het debat, en het is ondenkbaar (of in ieder geval hoogst verdacht) om over slavernij te schrijven zonder rekenschap te geven van een traditie van academische kritiek die minstens teruggaat tot W.E.B. DuBois. Niemand verwacht dat uit die botsing snel consensus zou kunnen komen, zeker niet in een land waarin de scheidslijnen, taal en symboliek van een over de slavernij uitgevochten burgeroorlog 150 jaar later nog altijd springlevend zijn. In dit artikel wil ik een paar persoonlijke observaties delen die voortkomen uit mijn participatie in slavernijonderzoek in deze twee heel verschillende academische contexten (aan de VU, het IISG, de University of Pittsburgh en Harvard).

\section{'Het grote slavenhandelssprookjesbos'}

Mijn eigen publieke entree in het Nederlandse slavernijdebat verliep niet geheel vlekkeloos. In 2014 was het precies tweehonderd jaar geleden dat Willem I per decreet de slavenhandel afschafte. De Britten waren Nederland daarin zeven jaar voor en voerden een agressieve internationale campagne om al hun Europese concurrenten te dwingen om aan de nieuwe standaard te voldoen. Tegenover Nederland stelden zij de afschaffing van de slavenhandel als voorwaarde voor de teruggave van een aantal koloniën, waaronder Suriname, die Groot-Brittannië tijdens de napoleontische oorlogen bezet had gehouden. Op 14 juni 2014 werd het daaruit volgende decreet in Zeeland plechtig herdacht. Ikzelf had in de maanden die daaraan voorafgingen net een aantal dikke dossiers doorgenomen over het scherpe debat in 1797 in de Nationale Vergadering over slavernij, de lauwe discussies die volgden op de formele afschaffing van de slavenhandel in 1814, en de pogingen tot voortzetting van de slavenhandel langs andere routes in de jaren die volgden. Wat mij daarin vooral opviel, was de grote terughoudendheid van de toenmalige Nederlandse regering om aan het koninklijk besluit maatregelen te verbinden waardoor de slaventoevoer naar Suriname ook daadwerkelijk zou stoppen. Het leek me dan ook merkwaardig om het moment 1814 via een herdenking speciale status toe te kennen, vooral in een Nederlandse context waarin de eigen rol in de slavernij doorgaans zo sterk werd gebagatelliseerd. Het deed me denken aan een uitspraak van de beroemde Caraïbische historicus Eric Williams. Hij merkte ooit schamper op dat, kijkend naar de wijze waarop Britse historici schreven over de humanitaire triomf van het abolitionisme, het wel leek alsof de Britten al die tijd alleen maar aan de slavenhandel mee hadden gedaan om ooit het plezier te smaken deze af te kunnen schaffen.

Wellicht een beetje rechthaberisch, schreef ik samen met Tamira Combrink een stukje op de opiniepagina van de Volkskrant over de misplaatstheid van het herdenken van deze afschaffing die nauwelijks een afschaffing was ('Slavenhandel 
kreeg juist doorstart in 1814', de Volkskrant 14 juni 2014). In de wetenschapsbijlage van NRC werd ik over hetzelfde onderwerp geïnterviewd ('Nederlandse slavenhandel ging na 1814 gewoon door', NRC 12 juni 2014). De feiten die aan ons argument ten grondslag lagen, waren niet nieuw door ons ontdekt en in de historische literatuur ook niet omstreden. Hoewel de slavenhandel in 1814 officieel werd afgeschaft, volgde pas in 1818 een wet waarin de deelname daaraan ook daadwerkelijk tot strafbaar feit werd gemaakt. Een speciale clausule maakte expliciet uitzondering voor slavenhandel die niet tussen Afrika en Amerika, maar binnen het Caraïbisch gebied plaatsvond. Deze loophole zorgde ervoor dat Surinaamse slavenhouders ook na 1818 nog jarenlang legaal nieuw aangevoerde mensen konden kopen. Pas in de tweede helft van de jaren twintig in de negentiende eeuw sloot de Nederlandse regering deze mogelijkheid onder grote Britse diplomatieke druk af, maar van harte ging dat zeker niet. Over de vraag hoe het moment 1814 in deze context gezien zou moeten worden, lopen de meningen uiteen. Maar dat 1814 voor de geschiedenis van de Nederlandse slavernij eigenlijk een non-moment was, daarover was eigenlijk iedereen het eens - en niemand bracht dit nadrukkelijker onder woorden dan Piet Emmer (Emmer, 1981). Ondanks dat reageerde Emmer in de Volkskrant opvallend hard op de door Tamira Combrink en mijzelf geformuleerde kritiek. In een stuk dat gepubliceerd werd onder de titel 'Afschaffen slavenhandel blijft wonder', stelde hij:

'Er zijn maar weinig wetten die internationaal zo veel effect hebben gesorteerd. Daarnaast waren ze irrelevant, niet in het Atlantische gebied, maar in Afrika. Daar namen de slavenhandel en de slavernij in omvang toe, want door de sterk verminderde uitvoer via de Atlantische kust daalden de prijzen op de binnenlandse slavenmarkten, waardoor meer Afrikanen het zich konden veroorloven om slaven te kopen. Daarover zwijgen Brandon en Combrink, want dan zouden ze "de blanke beschaving" maar in een gunstig daglicht stellen.' ('Afschaffen slavenhandel blijft wonder', de Volkskrant 21 juni 2014)

De coup de grâce in Emmers artikel was echter niet het bevragen van de eerbaarheid van onze motieven in de slotregel, maar zijn diskwalificatie van ons als wetenschappers, en daarmee ons recht van spreken binnen de grenzen van het Nederlandse debat zelf. Niets is in het licht van de hang naar empirie in het Nederlandse onderzoek dodelijker dan de volgende opmerking:

'Brandon en Combrink menen dat de interkoloniale slavenhandel nauwelijks is bestudeerd en daarom veronderstellen ze gemakshalve maar dat die handel zo omvangrijk was dat de afschaffingswetten irrelevant waren. Behendig vermijden ze weer het noemen van aantallen met uitzondering van de 18 duizend slaven die na 1816 nog naar Suriname zouden zijn gebracht, een getal duidelijk afkomstig uit het grote slavenhandelssprookjesbos.' (idem)

Niet ongevoelig voor de beschuldiging van empirisch broddelwerk, zonk de moed mij bij lezing van die laatste zin aardig in de schoenen. Een dag lang pijnigde ik op een vakantieadres in Spanje mijn hoofd over de vraag hoe wij zo stom hadden 
kunnen zijn om zomaar dit blijkbaar willekeurige cijfer van 18.000 de discussie in te slingeren, een cijfer dat mijzelf bovendien volledig onbekend voorkwam. Dat laatste bleek te kloppen. Bij nalezing van ons eigen artikel werd duidelijk dat wij dit verzonnen cijfer helemaal nergens genoemd hadden. In plaats daarvan hadden we gesteld dat er tussen 1816 en 1827 in totaal 12.000 mensen als slaaf in Suriname werden ingevoerd, een getal dat in alle literatuur wordt gehanteerd. De opinieredactie van de Volkskrant gaf ons helaas geen ruimte voor repliek, zelfs niet voor de paar regels die we in gedachten hadden.

Daarmee was de kous wel af, wat betreft de discussie over 1814. De sprekers op de plechtige herdenking in Zeeland verbaasden zich over dat 'zure stukje' in de krant. Moesten we niet blij zijn dat er überhaupt een herdenking was? Van een vooraanstaande collega op het IISG kreeg ik een schouderklopje, want publiekelijk afgebrand worden door Piet Emmer hoort er nu eenmaal bij als je in Nederland iets over slavernij wilt zeggen, zoals ook mijn collega's Karwan Fatah-Black en Matthias van Rossum kort daarvoor al hadden ondervonden (Fatah-Black \& Van Rossum, 2012; Emmer, 2012). Alleen een beetje dom dat we het Emmer blijkbaar zo makkelijk hadden gemaakt door 'zo slordig met cijfers om te gaan'. De onderliggende discussie over de betekenis van 1814 als historisch moment was snel vergeten. Ironisch genoeg past het geheel daarmee perfect bij het door Guno Jones geschetste beeld van een discursief landschap waarin voor fundamentele inhoudelijke interpretatiekwesties lang niet altijd ruimte is, maar des te belangrijker is wie de grens mag bewaken tussen 'onaantastbare wetenschappelijke feiten' en het 'grote slavenhandelssprookjesbos', wie op voet van gelijkheid toegang heeft tot het academische debat en wie niet.

\section{Richtingenstrijd als positieve bagage}

Heel anders was de toon van de discussie op de University of Pittsburgh, waar ik vanaf september 2014 anderhalf jaar kon werken aan mijn eigen project over racialisering, slavernij en contacten tussen verschillende onderdrukte groepen in de Nederlandse Atlantische wereld. Een van de factoren die het debat in de VS anders maken, is kritische massa. Ondanks de groei van het aantal onderzoekers dat 'iets' met slavernij doet, en ondanks de grote publieke aandacht voor dit type onderzoek, blijft het thema in Nederland toch min of meer een niche-onderwerp. Dat ligt heel anders in de VS, waar zelfs op een middelgrote, overwegend witte geschiedenisafdeling als die van Pitt makkelijk een zaaltje te vullen was met slavernijonderzoekers. Bovendien sprak vanzelf dat 'slavernij' niet een afgebakend historisch onderzoeksveld is, maar een van de grondthema's van de geschiedenis dat daarom ook vanuit een grote hoeveelheid verschillende specialismen te benaderen valt. De zeer regelmatige lezingen en seminars over aan slavernij gerelateerde thema's werden bezocht door Atlantische historici, afrikanisten, collega's uit Afro-American studies en critical race studies, en amerikanisten, wat automatisch al leidde tot een diversificatie van standpunten en benaderingen. Dat werd nog versterkt door de aanwezigheid van prominente onderzoekers met soms lijnrecht tegenovergestelde interpretaties van de slavernij, waardoor ook de begin- 
nende onderzoekers automatisch de druk voelen zich expliciet te verhouden tot de grote stromingen binnen het debat. In het geval van Pitt werden die verschillende stromingen gepersonifieerd door de bekende linkse historicus Marcus Rediker aan de ene kant (schrijver van onder andere The Slave Ship: A Human History) en Seymour Drescher (een zeer gerespecteerde historicus van het abolitionisme en criticus van het werk van Eric Williams) aan de andere.

Dat er geen reden is om het debat in de VS te idealiseren, mag duidelijk zijn uit de daar altijd aanwezige onderstroom van nostalgie naar het Oude Zuiden, inclusief binnen een substantieel deel van de politiek en wetenschap. Bovendien is Pitt noch Harvard, waar ik later een semester verbleef, een graadmeter voor de sfeer aan een gemiddelde liberal arts college in de Mid-West. Toch heeft het nut om, hoe anekdotisch ook, een aantal in het oog springende verschillen te benoemen. Een eerste gaat over de zelfdefiniëring van het veld en de breedte van de vraagstelling. Kwame Nimako, Amy Abdou en Glenn Willemsen merkten al eens op dat voor het Nederlandse debat over slavernij eigenlijk altijd één kwestie doorslaggevend is gebleven: de vraag wat het allemaal nu eigenlijk opleverde (Nimako, Abdou \& Willemsen, 2014, 34-36). Hoewel de vraag naar de betekenis van de slavernij voor de Nederlandse economie en kapitalistische ontwikkeling meer in het algemeen ook voor mij als economische historicus altijd een kernthema is geweest, is het duidelijk dat het slavernijdebat in bredere zin juist sterk gebaat zou zijn met veel meer kennis over de sociale geschiedenis van het fenomeen: de leefwereld van degenen die tot slavernij werden gedwongen en hun verzet, maar ook de langdurige patronen van dominantie en racisme die voortkwamen uit de pogingen om slavernij te bestendigen. Natuurlijk is daarover ook voor het Nederlandse slavernijverleden heel wat onderzoek gedaan, binnen en buiten de academische mainstream. Maar zoals Nimako, Abdou en Willemsen opmerkten, blijft de wetenschappelijke status van dit soort vraagstukken in Nederland toch hardnekkig achtergesteld bij wat zij de 'boekhoudersbenadering' noemen. Dit ligt in de VS heel anders, waar de sociale, politieke en ideeëngeschiedenis van de slavernij altijd een zeer prominente plek in de wetenschappelijke discussies hebben ingenomen. Een van de thema's waarop dit verschil het duidelijkst is, is dat van ras en racisme. De Amerikaanse onderzoekster Alison Games merkte in haar nawoord van een recent verschenen bundel over 'connecties in de Nederlandse Atlantische wereld' voorzichtig op dat het wel merkwaardig was dat er gekozen was voor een benadering die 'ended up privileging Europeans and European activity in the Atlantic world', waardoor slaven, slavernij en de oorspronkelijke bewoners van het Amerikaanse continent 'do not receive as much attention as one might have anticipated' (Games, 2014, 369). De tendens om de Atlantische wereld vooral te blijven bekijken vanuit het perspectief van Europese handelaren, gecombineerd met het nauwelijks problematiseren van ras in de Nederlandse slavernijdiscussie, heeft grote gevolgen voor de beoordeling van de doorwerking van de slavernij. Waar het in de Noord-Amerikaanse context weinig controversieel is om slavernij te beschouwen als kerningrediënt voor moderne ongelijkheid en racisme, wordt dit in de Nederlandse context al snel afgedaan als geforceerd. Natuurlijk zijn de twee geschiedenissen anders, zowel gezien de directe fysieke aanwezigheid van slavernij op het grondgebied van de huidige VS als door de specifieke karaktereigen- 
schappen van de emancipatiestrijd van de zwarte Amerikaanse bevolking voor en na de afschaffing van de slavernij. Maar dat rechtvaardigt nog niet het handhaven van een blinde vlek voor de racialiseringsdynamiek die ook de Nederlandse slavernij onmiskenbaar had, en daarmee de illusie van 'witte onschuld' die de antropologe Gloria Wekker voor het moderne Nederland recent zo scherp ontleedde (Wekker, 2016).

Uiteraard is er geen sprake van dat over deze grote thema's gestreefd zou kunnen worden naar consensus. Precies daarom is het voor Amerikaanse wetenschappers ook volledig acceptabel dat er elk jaar weer een nieuwe stroom boeken verschijnt op basis van al lang bekende bronnen over de slavenhandel of over de plantagesector, en kijkt niemand op van een zoveelste artikel waarin de autobiografieën van de ontsnapte slaven Frederick Douglass en Mary Prince opnieuw worden ontleed. Zoveel historici, zoveel inzichten. Het naast elkaar bestaan van geprofileerde historische benaderingen en het stellen van door de huidige tijd ingegeven vragen hoeven bovendien geen belemmering te zijn voor gedegen empirisch onderzoek, zoals sommige Nederlandse historici lijken te denken. In Pittsburgh woonde ik de presentatie bij van een paper door een van de promovendi van Marcus Rediker, die gegrepen door diens brede visie op de internationale verbanden in slavenverzet een groot speculatief verhaal hield over marronage. Seymour Drescher stak zoals bij elke presentatie als eerste zijn hand op - het recht van de oudste. In zijn bijdrage plaagde hij de promovendus vriendelijk maar ongenadig. 'This might have happened, that could have been, possibly this, probably that. Waar blijft je argumentatie met zoveel maybe's?' Een paar weken later was het de beurt aan dezelfde promovendus om Drescher na een lezing fijntjes te wijzen op de onjuiste weergave van een idee van de zwarte marxistische geschiedschrijver van de Haïtiaanse revolutie C.L.R. James. Pluriformiteit leidt niet automatisch tot beter onderzoek. Maar het biedt wel een kader voor wederzijdse kritische bevraging, zonder de verwachting dat verschillen in interpretatie zo snel mogelijk worden gladgestreken. Dat creëert ruimte voor nieuwe benaderingen, en vergroot de mogelijkheden voor de inhoudelijke verrijking van bestaande academische inzichten door perspectieven van buiten.

\section{Conclusie}

In een optimistisch rapport, in 2014 geschreven in opdracht van de gemeente Amsterdam, constateerde Alex van Stipriaan dat de kennis over het slavernijverleden onder het grote publiek zeker was toegenomen (Van Stipriaan 2014). Hij plaatste daarbij wel een aantal kritische kanttekeningen. Begrip voor de doorwerking van de slavernij op de huidige samenleving was te beperkt, van inhoudelijke verdieping was onvoldoende sprake, en slavernij was ook nog geen gedeeld thema geworden. In het rapport zelf beschreef Van Stipriaan de ongunstige uitwerking van landelijk beleid, zoals de intrekking van de rijkssubsidie aan NiNSee, maar ook de gelijktijdige positieve beweging in het wetenschappelijke onderzoek. Die laatste trend heeft zich in de laatste jaren zeker doorgezet. Meer historici houden zich bezig met slavernij, er is ruimte voor nieuwe vragen en benaderingen. Hard- 
nekkige patronen van een op consensus gerichte academische debatcultuur en geslotenheid voor nieuwe benaderingen van 'de feiten' - in een wetenschappelijk landschap dat bovendien onder historici erg wit blijft - zijn zeker niet zomaar doorbroken. Toch is er reden tot optimisme over de toekomst van het onderzoek naar de doorwerking van slavernij en de mogelijkheden die daaruit voortkomen voor verdieping van kennis. De vraag of dat er ook toe zal leiden dat slavernij een 'gedeeld thema' wordt, is veel ingewikkelder. Het omvangrijkere onderzoek naar het slavernijverleden aan Amerikaanse universiteiten heeft zich bepaald niet vertaald in een afname van openlijk racisme of van onwetendheid en onbegrip over het eigen verleden. En ook in Nederland lijkt de politieke trend eerder omgekeerd evenredig aan de voortgang van de kennis. Maar misschien is het idee dat nieuwe kennis rond een thema van zulke grote historische tegenstellingen en strijd als de slavernij zich onmiddellijk zou moeten vertalen in een 'gedeeld verhaal' ook wel weer een typisch Nederlandse consensusgedachte. Want als het Amerikaanse voorbeeld ons iets kan leren, is het dat gelijkheid eerst komt en dan pas de verbinding.

\section{Literatuur}

Emmer, P.C. (1981). Abolition of the abolished. The illegal Dutch slave trade and the mixed courts. In D. Eltis \& J. Walvin (red.), The abolition of the Atlantic slave trade. Origins and effects in Europe, Africa, and the Americas. Madison: University of Wisconsin Press, 177-192.

Emmer, P.C. (2012) Winst in de marge? Reactie op Rossum, M. van en Fatah Black, K. 'Wat is winst? De economische impact van de Nederlandse trans-Atlantische slavenhandel'. TSEG, 9 (4): 64-70.

Fatah-Black, K., \& Rossum, M. van (2012). Wat is winst? De economische impact van de Nederlandse trans-Atlantische slavenhandel. TSEG, 9 (1): 3-29.

Games, A. (2014). Conclusion. A Dutch Moment in Atlantic Historiography. In: G. Oostindie \& J.V. Roitman (red.), Dutch Atlantic Connections, 1680-1800. Linking Empires, Bridging Borders. Leiden/Boston: Brill, 357-373.

Jones, G. (2012). De Slavernij is onze geschiedenis (niet). Over de discursieve strijd om de betekenis van de NTR-televisieserie De Slavernij. BMGN/Low Countries Historical Review, 127 (4): 56-82.

Mathijssen, N. (2018). Laat historici ontvankelijker worden voor afwijkende perspectieven: Interview met Susan Legêne. Over de Muur , 4-10. https://overdemuur.org/laathistorici-ontvankelijker-worden-voor-afwijkende-perspectieven/, geraadpleegd op 17 mei 2019.

Nimako, K., Abdou, A., \& Willemsen, G. (2014). Chattel slavery and racism. A reflection on the Dutch experience. In: Ph. Essed \& I. Hoving (red.), Dutch Racism. Amsterdam: Rodopi, 33-52.

Stipriaan, A. van (2014). Slavernij, daar willen we meer van weten. https://alexvanstipriaan. com/wp-content/uploads/2016/01/2014-Slavernij-daar-wil-je-meer-van-weten-def. pdf, geraadpleegd op 17 mei 2019.

Wekker, G. (2016). White Innocence. Paradoxes of Colonialism and Race. Durham/Londen: Duke University Press. 